\title{
EL HISPANISMO Y LA LITERATURA ESPAÑOLA EN EL ÁMBITO ACADÉMICO LATINOAMERICANO. UNA VISIÓN DESDE ARGENTINA
}

\author{
Raquel Macciuci \\ La Plata
}

HisPANISMO E HISPANISMOS

Deseo comenzar mi trabajo reiterando la felicitación a los organizadores del Coloquio Internacional "La Hispanística y el desafío de la globalización" por la feliz iniciativa de brindar un homenaje al profesor Dieter Ingenschay con un tema que tan bien lo representa, como especialista reconocido y apreciado en el dilatado y diverso territorio del hispanismo. Y agradeciendo nuevamente la invitación, así como la oportunidad de explicar el concepto y la práctica del hispanismo en Latinoamérica desde la perspectiva de una cátedra de Literatura Española — es decir, literatura peninsular, de España— en una universidad argentina.

Quizás sorprenda que, en el marco de una reunión científica dedicada a los desafíos presentes y futuros del hispanismo, el título de mi exposición apele a una sistematización de literatura atada a las fronteras nacionales y, por tanto, a concepciones que hoy están sometidas a múltiples transformaciones. Espero que al final mi enfoque quede justificado.

Intentaré en primera instancia precisar el significado de hispanismo e hispanista en el ámbito académico latinoamericano ${ }^{1}$, pues su alcance difiere del que adquiere en Europa, en Estados Unidos y en la misma España. Igualmente, difieren las connotaciones y el aura que rodea a las tres áreas o especialidades

\footnotetext{
${ }^{1}$ No utilizaré el término hispanistica porque no es usual en Argentina y entiendo que sirve para designar la especialización en lenguas y literaturas hispánicas en países pertenecientes a otras áreas lingüísticas y culturales.
} 
del hispanismo que tienen presencia en las universidades argentinas ${ }^{2}$; esto es, las literaturas argentina, latinoamericana y española. Sus solos nombres evocan líneas demarcatorias ligadas a la historia de América Latina, al pasado colonial y al discurso eurocentrista; por consiguiente, no funcionan de la misma manera dentro y fuera de nuestro continente. La expresión intentar, por tanto, no es aleatoria: hay una gran distancia entre una definición de manual o de diccionario y las variaciones y matices que adquiere el concepto según los factores intervinientes y el contexto de enunciación.

Ser hispanista y ser profesor a cargo de una asignatura de Literatura Española, cualquiera sea el período, son sinónimos en muchos países de Latinoamérica. Sin embargo, decirse "hispanista", expresión infrecuente, despierta prevenciones ligadas a la experiencia colonial y a los litigios en torno a la batalla por la soberanía y la identidad cultural que empezó a librarse después de la independencia política de los países americanos (Romanos 2004; Chicote 2013).

Si bien definirse como especialista en literatura española no despierta - o despierta menos - ecos asociados a la exmetrópoli y a un largo historial de su pretendida autoridad en cuestiones culturales y lingüísticas, tres décadas atrás debió afrontar otra rémora: el halo de desprestigio de la disciplina, asociada a una desactualización teórico-crítica crónica (vinculada, no siempre, a la cultura del franquismo) que la presencia de numerosos exiliados republicanos no pudo contrarrestar (Diego 2004; Romanos 2004). Por otro lado, la irrupción de una ingente producción cultural latinoamericana, que no ha cesado de crecer y ganar lectores, actuó en desmedro del interés por la cultura española dentro y fuera del territorio americano. Debe añadirse que no fue ajena al descrédito la repercusión en torno a las batallas del idioma, de larga memoria, que alimentaron la visión estereotipada de lo español —alimentada por cierta presunción rioplatense- y obturaron un acercamiento complejo y matizado a la cultura peninsular (Diego 2004; Pastormerlo 2006; Macciuci 2006a).

${ }^{2} \mathrm{Al}$ contrario de lo que sucede en los departamentos de Estados Unidos o Europa, no existen cátedras dedicadas exclusivamente a las literaturas gallega, catalana o vasca, salvo con un estatuto especial que se mencionará más adelante. 
Dando un salto en la línea del tiempo, al promediar la segunda década del siglo Xxi la literatura española ha recuperado la consideración en la currícula académica y legitimado su lugar en el área de las letras hispánicas, junto a las literaturas argentina y latinoamericana, cada una con sus rasgos distintivos pero emparejadas en cuanto a la inserción en un contexto teórico y cultural que alienta la revisión de las fronteras y de los compartimentos disciplinares clásicos en pos de un enfoque integrador y transversal.

Sin embargo, la tendencia a la disolución de las disciplinas tradicionales no es óbice para que los planes de estudios de las carreras de Letras - $\mathrm{O}$ Literatura, o Filología...- en el nivel universitario deban atenerse al muy arraigado esquema de literaturas organizadas por nacionalidades, hecho que determina los saberes específicos y el curriculum vitae de los profesores. En el área de las literaturas hispánicas continúa vigente y sólida la división tripartita básica: Literatura Española, Literatura Latinoamericana ${ }^{3}$ y Literatura Argentina, esquema que propugna el conocimiento riguroso y altamente especializado de la historia y singularidades de cada uno de los tres sistemas literarios.

La perspectiva de mi trabajo se centrará preferentemente en cómo las circunstancias históricas, las coordenadas geográficas y la tradición académica inciden en el concepto de hispanista argentino, determinan el lugar que ocupa la literatura espańola en los planes de estudios y repercuten en el perfil del profesor e investigador dedicado a estudiar la literatura producida en España. A partir de reflexiones previas que he publicado en distintas oportunidades, justificaré la hipótesis sobre una doble condición de alteridad mediante una suerte de ejercicio de hispanismo comparado.

${ }^{3}$ Utilizo la fórmula "literatura latinoamericana” por ser la preferida por sus especialistas, frente a "hispanoamericana" o "iberoamericana". Pese a que en su origen el vocablo "Latinoamérica” estuvo asociado a la operación de Francia con el fin de participar del mapa cultural americano (union latine), se acepta que la revolución cubana enraizó el término y le dio legitimación, frente a las otras dos alternativas que remiten a un mapa real y simbólico anterior a la independencia. 
Primera alteridad: LA Literatura ESPAÑola Y LA LENGUA DE LOS CONQUISTADORES

De lo dicho en las líneas precedentes puede advertirse que las letras de Espańa tienen un estatuto ambivalente, una condición otra en el concierto de los planes de estudios universitarios argentinos: por un lado, se sitúa en la familia de las literaturas en lengua castellana y es reconocida como el sustrato común del cual surgen las literaturas nacionales de América Latina —aun con las salvedades y menciones obligadas a otras fuentes y aportaciones esenciales. Pero al mismo tiempo, es percibida como una literatura extranjera, que contiene rasgos de las otras literaturas europeas que integran los planes de estudio — francesa, italiana, alemana, inglesa, etc. — cuyas referencias culturales no establecen lazos de identidad directos con la América hispanohablante. La literatura española es, por tanto, una literatura familiar y cercana, pero sus problemas surgen y se intentan explicar en el marco de referencia de las sociedades del Viejo Mundo. Ya se ha visto que comparte una lengua común con Latinoamérica, pero también una historia de enfrentamientos y guerras de independencia en el bando opuesto, en un mapa en el cual la geografía acentúa la diferencia y la distancia.

Otra es la situación fuera de América Latina: como objeto de estudio en las universidades europeas, la literatura espańola forma parte de un corpus panhispánico en el cual coexiste con una fecunda literatura latinoamericana a la que se ha unido la literatura hispana de los Estados Unidos, cuestión que retomaré más adelante.

En un tablero cambiante según las coordenadas desde donde se toma la fotografía, se verifica sin embargo una circunstancia de importante valor simbólico y político que se mantiene prácticamente inalterable a lo largo del tiempo y de los puntos cardinales, rubricando el halo de extranjería y la raíz peninsular del hispanismo y, en consecuencia, la otredad respecto de los países del Nuevo Mundo. Así como un congreso de literatura francesa celebrado fuera de Francia contará con el aval y el patrocinio de la embajada de aquel país, el acompañamiento de las representaciones diplomáticas o de sus organismos para la difusión de su cultura (como la Alliance Française) e incluso empresas comerciales, subrayado por logotipos y emblemas galos; y la Embajada de Alemania y el Goethe-Institut harán acto de presencia si 
el encuentro es sobre germanística; la de China si fuera sobre sinología...; con la misma lógica, los congresos de hispanistas celebrados en Latinoamérica o Europa cuentan sistemáticamente con el patrocinio de la Embajada de España, de instituciones como la Asociación Española de Cooperación Internacional (AECI) y, si se trata de un país no castellanoparlante, del Instituto Cervantes. Teniendo en cuenta que la herencia literaria es clave para la constitución del capital cultural y la identidad de una nación, sin dejar simultáneamente de imbricarse con intereses económicos y políticos a nivel de estado, se entenderá mejor el estatuto de la literatura española en América Latina, y la naturaleza de la frontera simbólica que se erige a pesar de los esfuerzos por unificar la gran familia castellanoparlante ${ }^{4}$.

La distancia se profundiza cuando se revisan las nociones de hispanismo, hispanista e hispanidad. El término hispanismo se resignificó a partir de un hecho progresista, ya que la creación en 1962 de la Asociación Internacional de Hispanistas en la Universidad de Oxford fue luego el anclaje para que

${ }^{4}$ En el XVIII Congreso de la Asociación Internacional de Hispanistas (AIH), celebrado en julio de 2013 en la Universidad de Buenos Aires, tuvo lugar un episodio sumamente representativo tanto de la gravitación del pasado como de la imbricación entre las políticas de Estado presentes, la literatura y el hispanismo en América Latina: en el acto inaugural, entre varios discursos pronunciados por las autoridades a favor del conocimiento como fuente de amistad entre los pueblos, el presidente de la AIH hizo suyas las palabras de Ángel Rosenblat, para quien el estudio del legado cultural español era la vía más adecuada para vencer los recelos dejados por el pasado colonial y las guerras de la independencia americana. Minutos antes, el decano de la Facultad de Filosofía y Letras había instado a que el hispanismo reflexionara también sobre acontecimientos que trascienden la esfera académica, tal como el trato agraviante e improcedente que varios países de la Unión Europea habían dispensado al primer mandatario de la República de Bolivia, Evo Morales, en las semanas previas al congreso (Ruiz 2013). El episodio había tenido lugar cuando Francia, Italia, Portugal y Espańa, siguiendo instrucciones de los Estados Unidos, obstaculizaron de diferentes maneras el normal regreso del presidente desde Moscú a La Paz, con el argumento de que en el avión en que viajaba ocultaba al entonces muy buscado exempleado de la Agencia de Seguridad Nacional estadounidense, Edward Snowden. La prensa registraba alternativas de similares connotaciones — merecedoras de un tratamiento aparte- en las jornadas del VII Congreso Internacional de la Lengua Espańola, celebrado en Puerto Rico entre el 11 y 19 de marzo de 2016. El incidente se originó cuando Felipe VI, rey de España, asignó al estado asociado el estatuto de territorio perteneciente a los Estados Unidos, desvinculándolo del área geográfica y cultural latinoamericana (Ruiz Mantilla 2016). 
los exiliados españoles republicanos radicados en Estados Unidos tuvieran un ámbito desde el cual rescatar y fortalecer una herencia cultural que la dictadura les negaba en su propia tierra (Álvarez Barrientos 2010). Al mismo tiempo, también la dictadura de Franco apelaba al vocablo para identificar a las instituciones destinadas a propagar la cultura del régimen en el exterior desde postulados asentados en una rancia orientación católico-nacionalista. En Argentina hubo un Instituto de Cultura Hispánica cuya prédica se sustentaba en posiciones retrógradas, acentuadas por una retórica enfática. Asimismo, es posible recopilar un nutrido conjunto de textos de autores de una u otra orilla donde el vocablo hispanidad queda asociado a ideas y prédicas de indudable sesgo ultramontano.

Por otra parte, ya en tiempos posdictatoriales en España, el originariamente progresista y ponderado concepto de hispanista comenzó a eclipsarse en Estados Unidos cuando los departamentos de Estudios Culturales desplazaron a los departamentos de Estudios Hispánicos y propugnaron volcarse a la literatura de la América hispana desde un nuevo marco teórico.

A la rama peninsular del país del norte le quedó el estigma de la desactualización teórica y del conservadurismo ideológico a causa de su afán por defender el lugar de la literatura escrita en España y propugnar la lectura de obras canónicas (Gies 2001; Oleza 2004) o por ignorar las relaciones entre literatura y sociedad (Delgado 2008). No obstante, algunos juicios perciben una realidad prometedora fundada en el crecimiento en todo el mundo de los centros y las cátedras para la enseñanza del español (Pope 2008). Las dos perspectivas son ciertas y complementarias, porque aluden a dos parcelas distintas del problema: una registra el crecimiento de los hablantes y estudiantes de la lengua española en el mundo, la otra responde a la preocupación por estudiar y dar respuesta a la presencia de una numerosa población en su territorio. Esta nueva demanda ha dado origen a una tercera especialización dentro del hispanismo que se suma a las ramas peninsular y latinomericana, la US-latina, cuyo campo está constituido por las producciones culturales de raíz latina, las cuales no siempre utilizan el castellano, ni sus autores son siempre de origen hispano (Gies 2001).

En España, el adjetivo hispánico incluye temas y asuntos de todo el ámbito de habla española, sea peninsular o americano, perspectiva que no es ajena a políticas culturales tendientes a aumentar el intercambio y la cooperación 
pero también a ganar en peso económico y comercial. Similar alcance tiene el concepto hispanista, que hoy hace referencia al estudioso o interesado en cuestiones hispánicas en sentido amplio, pese a que en un comienzo designaba únicamente a los estudiosos extranjeros de la literatura, fundamentalmente peninsular, e incluía el aprendizaje de la lengua (Romanos 2004; Pozuelo Yvancos 2009). Una prueba de la novedad del término en España es la frecuencia con que se escucha decir al especialista en literatura española que no se siente identificado ni cómodo con este adjetivo aplicado a su condición. En cambio, en las universidades europeas, el hispanismo albergó desde el comienzo tanto a los interesados por España como por Latinoamérica; en consecuencia, las asociaciones de hispanistas tienen igual competencia para los temas de ambos lados del océano, aunque en los hechos se aprecia una gravitación mayor de la literatura en castellano de todo el continente americano, invirtiéndose así el orden histórico, ya que la consolidación del hispanismo como objeto de estudio derivó de la atracción de alemanes, franceses e ingleses por la exótica Espańa y no por la fascinante pero aún poco conocida América Latina. La disolución de las demarcaciones nacionales y el desarrollo de una fuerte línea comparatística orientada hacia los estudios intermediales son dos rasgos descollantes de la hispanística europea actual ${ }^{5}$.

Es momento de analizar la situación en Argentina donde, como se anticipó, hispanista y especialista en literatura española son sinónimos, o casi sinónimos. Los congresos y actividades anunciados bajo el rótulo de "hispanismo" tradicionalmente han convocado al especialista en literatura española, y la Asociación Argentina de Hispanistas (AAH) fue creada en 1986 gracias a la iniciativa de distintas cátedras de Literatura Española. A causa del valor inclusivo del término y por la influencia de la $\mathrm{AIH}$, no faltan en este organismo ni en las actividades que programa especialistas del área latinoamericana o argentina, pero numéricamente no alcanzan cifras representativas. Hasta pocos años atrás era infrecuente, por no decir insólito, que un experto en literatura latinoamericana o argentina reconocido como referente en su

\footnotetext{
${ }^{5}$ Soy consciente de la diversidad de los hispanismos europeos y del riesgo de formular aseveraciones de alcance general.
} 
materia participara de un congreso de la $\mathrm{AIH}$ o de la $\mathrm{AAH}^{6}$. Contrariamente, los especialistas en literatura española, sin distinción, consideran estos congresos como el espacio más genuino de su especialidad, los únicos dedicados mayoritariamente a temas, autores y problemas del sistema literario español. Actualmente, los congresos de la AAH continúan siendo el principal lugar de encuentro de especialistas en literatura española; el único donde se reúnen los expertos de los tres períodos preceptivos: medieval, siglos de oro (o temprana modernidad) y contemporáneo.

Pero al mismo tiempo, este panorama no es el mismo de algunas décadas atrás: en los últimos años se observa una deriva hacia otro modelo de hispanismo, en sintonía con las tendencias y la configuración del hispanismo internacional (Chicote 2013). Aunque las transformaciones son recientes y no permiten aún extraer conclusiones, es de rigor consignar que sectores representativos del hispanismo argentino también consideran oportuno abrir el ámbito del hispanismo a todos los especialistas en literaturas en lengua española; es decir, se proponen la difícil tarea de seducir a las áreas de Literatura Argentina y Latinoamericana para que asistan a sus congresos, dificultad que se explica a la luz de los antecedentes políticos e históricos mencionados más arriba.

Ignoro si el gesto inclusivo tendrá frutos prolongados; lo cierto es que no se trata de una política aislada. Hoy los Estudios Hispánicos en su sentido extenso se llaman al diálogo; son diversas las convocatorias a romper con la parcelación continental de los Estudios Hispánicos así como con las compartimentaciones nacionales (Chicote 2013). El propósito es sin duda razonable y apoyado en reflexiones teóricas que entienden como contradictorio y anacrónico reproducir las fronteras de los estados en el ámbito de la literatura y la cultura en la era de la comunicación global.

No obstante, el llamado al diálogo no está exento de las evaluaciones políticas que generan juicios disímiles sobre los puentes de ida y vuelta. Por ejemplo, el conocido proyecto "Diálogos transatlánticos", llevado adelante por Julio Ortega desde la Universidad de Brown, ha recibido opuestas

\footnotetext{
${ }^{6}$ Con temor a cometer olvidos injustos, deseo citar como excepciones los nombres de Ana María Barrenechea y Hugo Cowes, prominentes "hispanistas" no ligados a cátedras o ámbitos específicos de Literatura Española. Barrenechea no solo fue presidenta de la AIH, sino además la primera mujer en presidir el organismo.
} 
acusaciones de esconder solapados propósitos de hegemonía detrás de sus buenas intenciones.

A menudo, se consideran los Estudios Transatlánticos como un área donde cabe todo, sin faltar los estudios que se autodenominan transatlánticos pero que continúan una práctica crítica basada en concepciones trasnochadas de influencias y jerarquías. Hay voces en el campo que consideran que los Estudios Transatlánticos son una manera de apartarse de las características más europeas de la literatura peninsular para supeditarla a un latino-americanismo predominante en las universidades norteamericanas. Se oye también lo contrario: que los Estudios Transatlánticos no son más que una arremetida del viejo peninsularismo para recuperar cierta hegemonía en los departamentos de español (Fernández de Alba/Pérez del Solar 2006: 99)7

El tiempo permitirá evaluar los resultados de los intentos aperturistas del hispanismo argentino. Por lo pronto, el reciente congreso de la AIH, celebrado en Buenos Aires en julio de 2013, no contó con la presencia esperable de especialistas del país anfitrión, sin duda debido al costo de unos aranceles que, paradójicamente, no están hechos para la moneda de los hispanistas latinoamericanos. En cuanto a los invitados convocados para impartir las conferencias principales, estos provenían de diferentes áreas de las literaturas en lengua espańola, corroborando la tendencia internacional inclusiva y no centrada en la literatura ni en los especialistas de la península.

En cuanto a las reuniones científicas de la $\mathrm{AAH}$, puede observarse que en su IX congreso, celebrado en la Universidad Nacional de La Plata, la comisión organizadora local logró una importante presencia de expositores de todas las literaturas en espańol, gracias a circunstancias que no pueden, por el momento, considerarse estables. Como anécdota ilustrativa puedo testimoniar la expresión de extrañeza cuando felicité a varios colegas de literatura latinoamericana

\footnotetext{
${ }^{7}$ Sin intención de intervenir en la polémica con ligereza, me interesa apuntar que el reciente volumen de estudios reunidos del prestigioso profesor peruano (2010) es un diáfano exponente del nuevo rumbo del hispanismo norteamericano: la presencia de estudios sobre obras literarias de España es reducida, y la literatura es desplazada por temas y perspectivas críticas que responden más a los estudios culturales norteamericanos que a la tradición crítica desarrollada en la academia de Europa, Espańa o Latinoamérica. Una propuesta más anclada en la tradición crítica de la academia argentina y española se encuentra en Gallego Cuiñas (2012).
} 
y argentina porque al menos por tres años podrían autodenominarse hispanistas y exhibir la membrecía de la AAH.

En mayo de 2014 se celebró un nuevo congreso de la AAH, el décimo, con sede en la Universidad Nacional del Litoral. Un repaso apresurado del programa revela que se mantuvo el perfil histórico que caracteriza a estas reuniones científicas; es decir, el de un congreso especializado en la literatura española de los tres períodos clásicos, al que se suma, como viene siendo habitual en Argentina, una discreta presencia de historiadores, lingüistas y profesionales de la enseñanza del español como segundo idioma. Los expositores latinoamericanistas o de otros espacios disciplinarios no representaron una cifra elevada ni registraban concurrencia previa y continuada, hecho que sí se constata para el caso los participantes del hispanismo.

Por último, es preciso mencionar, aunque sin datos concretos, una tendencia igualmente sustancial del hispanista argentino en el presente: su comparecencia en ámbitos ajenos a su especialidad, sea en la forma de trabajos críticos o de comunicaciones en congresos nacionales e internacionales, creación de publicaciones de temática diversa, y otras numerosas actitudes indicadoras de la apertura hacia vertientes interdisciplinarias y transatlánticas.

\section{Segunda ALTERIDAD: El hisPanismo americano en El ESCENARio} DE LOS ESTUDIOS HISPÁNICOS INTERNACIONALES

El análisis del propio lugar de enunciación — periférico- de la crítica hispánica en Argentina no equivale a una ponderación programática y esencialista del des-centramiento; se trata, en todo caso, de evaluar las derivaciones de la alteridad constitutiva, desde la cual es posible hacer productivas las circunstancias insoslayables que operan en la construcción de un discurso crítico. La elemental evidencia de que el punto de mira influye en la percepción de un cuerpo puede convertirse en una baza estimulante. Es plausible entonces sostener que la distancia, material y simbólica, puede iluminar zonas del objeto que permanecen en penumbra en una focalización desde el centro. Cuando el interés es recíproco, las travesías entre las distintas coordenadas dan lugar a diálogos fructíferos entre el centro y la periferia, en una y otra dirección (Macciuci 2006c). 
Los estudiosos de la literatura española residentes en la América austral nos encontramos distante física y simbólicamente de la antigua metrópolis, investida del prestigio de "dueña de casa" y de la autoridad que conlleva ser la cuna de los escritores objeto de estudio. Igualmente lejos nos hallamos de los Estados Unidos, el foco que hoy disputa a España, y también a Europa, la hegemonía de los Estudios de Literatura Española y a América Latina los del latinoamericanismo.

La doble lejanía no impide que ambos polos ejerzan una decisiva influencia en el hispanismo austral, ya que en uno y otro centro se origina una producción intelectual especializada muy influyente, y para el caso de la literatura española, la más abundante, específica y con más altas posibilidades de llegada y circulación en nuestro medio, que no es igual en dirección contraria: una rápida lectura a la bibliografía de los libros especializados en literatura peninsular editados en España muestra la escasa presencia de estudios surgidos de los ámbitos de literatura española de América Latina, cuyas cátedras y asignaturas dedicadas a la especialidad alcanzan reunidas una elevada cifra. El intercambio más intenso tiene lugar entre los dos centros hegemónicos, al que debe agregarse el hispanismo germano; el prestigio de algunas instituciones y los nombres señeros del hispanismo del sur no son suficientes para obtener visibilidad entre las academias citadas. Prueba de ello es que la mayor parte de los trabajos que polemizan sobre el hispanismo se focalizan en debates mantenidos entre la academia española y norteamericana (vv. AA. 1995); en contadas ocasiones hacen referencia también a determinados países del resto de Europa (Macciuci 2006b). Basta consultar los sumarios de revistas especializadas o historias de la literatura española para comprobar que reproducen la misma hegemonía. En la misma dirección, los índices alfabéticos de las historias de literatura espańola arrojan a simple vista una abrumadora mayoría de especialistas del norte.

Las condiciones referidas no deben sorprender — la densidad de hispanistas es mayor en el área peninsular y en América del Norte- ni deben considerarse paralizantes para los especialistas alejados de los núcleos preponderantes, pues la gravitación y el dinamismo del hispanismo, en cualquiera de sus territorios de anclaje, se manifiesta en un intenso diálogo entre espacios académicos cuyas redes, gracias a las dimensiones más acotadas y a sus coincidencias en temas y líneas de trabajo, han podido realizar intercambios 
altamente especializados y prolongados en el tiempo. Si a la luz de los intereses que dominan en los espacios académicos mencionados, los lazos más sólidos de los hispanistas argentinos históricamente se han establecido con universidades de España y Europa, la afirmación de nuevas zonas del planeta en el clásico reparto de las hegemonías augura un afianzamiento de las periferias. En la América del Sur ilustra acabadamente esta realidad la vitalidad del hispanismo brasileño, apoyado por una firme política peninsular.

De la alteridad de las literaturas españolas en las universidades argentinas surgen algunos rasgos derivados de sus coordenadas: la particular realidad del hispanismo en nuestro medio académico, en conjunción con la tradición literaria argentina, nos permite trazar un mapa amplio e inclusivo de la literatura española, con entradas — mínimas, pero simbólicamente relevantesen la literatura gallega, catalana y vasca, sin tener que afrontar los conflictos sobre jurisdicciones y preeminencias que se darían en una facultad de España o de Estados Unidos. El reconocimiento de las literaturas no castellanas no vulnera el lugar preferencial de la lengua materna, lo cual no significa desconocer viejos litigios, o la existencia de viejas lenguas y nuevos mestizajes resultado del contacto con lenguas precolombinas ${ }^{8}$.

${ }^{8}$ La presencia de las literaturas catalana, gallega y vasca en la currícula de las universidades argentinas a primera vista puede parecer equivalente a la pugna de algunos departamentos hispanistas de academia norteamericana por incluir en el canon hispánico las literaturas no castellanas -es particularmente conocido el empeño de Joan Ramon Resina respecto del catalán (Gies 2001: 498-499). Pero el contexto en que se expresa la reivindicación en el norte es muy diferente y no se ajusta a la realidad lingüística y cultural argentina, y rioplatense en particular, en la que el castellano o español tiene el estatuto que le confiere ser el idioma oficial, la lengua materna de la mayor parte de la población y la principal lengua de comunicación. Por tanto, cuando se trata de letras o cultura española o peninsular, la expresada en castellano tiene la supremacía que deviene de estar escrita — con todas las variaciones que se conocen - en la lengua de Argentina, de uso absolutamente mayoritario entre los hablantes. Resta señalar al respecto que el carácter inclusivo del hispanismo de estas latitudes se manifiesta no solo en el tratamiento de autores pertenecientes a ámbitos lingüísticos no castellanos, sino también en la existencia de un sistema de cátedras libres que permite designar a especialistas idóneos para que impartan cursos y realicen actividades sobre contenidos no contemplados en la currícula de las carreras, entre ellos todas las culturas peninsulares de las autonomías (hay cátedras libres de Lengua y Cultura Catalana, Vasca, Gallega especialmente). 
También puede considerarse un resultado feliz de la mirada desde la periferia sobre la literatura española — probablemente gracias a la tradición crítica y al mestizaje genérico que han caracterizado la literatura argentina desde sus textos fundacionales - que nuestras asignaturas delineen un corpus de obras y autores menos canónicos, habiéndose anticipado a menudo a los cambios en el parnaso y en la agenda crítica que se producirían más tarde en España, en una clara muestra de que los hispanismos no peninsulares se muestran más dúctiles y menos sujetos a la autoridad de la institución literaria. En el juego de tensiones entre tradición y apertura del canon, no creo sea puro azar que varios estudios precursores sobre escritores, géneros o modalidades poco admisibles en los repertorios clásicos hayan comenzado a ser estudiados fuera de España, favorecidos quizás por la "ajenidad" a las rivalidades del campo intelectual español y por la lejanía de la autoridad de las instituciones más conspicuas, que se muestran moderadas a la hora de aceptar los cambios, provengan de un lado o del otro del océano (Macciuci 2006c).

Decidir qué sea literatura o no, es el primer paso hacia la formación/ transformación del canon. La literatura hispanoamericana ha experimentado un gran desarrollo y reconocimiento internacional a partir del famoso boom novelesco; pero también ha visto aparecer, incluso consagradas por el Premio Nobel, otro tipo de escrituras-testimonio que no tenían cabida a priori en los baremos canónicos establecidos. La tensión entre el éxito de recepción de ciertos textos y la resistencia académica a incorporarlos a los programas oficiales ha sido grande al menos en España, y demuestra la necesidad de modernizar el canon (Caballero Wangüemert 2000: 63).

Se ha tratado de explicar hasta aquí el significado y extensión del término hispanismo en algunos países de América Latina, inseparable de su identificación con cátedras, departamentos o institutos de Literatura Española9. Las dudas que hayan podido quedar abiertas tienen otra vía de esclarecimiento a través de un instrumento revelador constituido por los programas de Literatura Española en la carrera de grado. Los contenidos de dichos programas

\footnotetext{
${ }^{9}$ La denominación del reconocido Instituto de Filología y Literaturas Hispánicas "Dr. Amado Alonso" de la Universidad de Buenos Aires encierra en el sema plural una concepción amplia que en la práctica está acotada por la existencia del Instituto de Literatura Argentina "Ricardo Rojas" y del Instituto de Literatura Latinoamericana.
} 
arrojan datos precisos que coinciden con el perfil del hispanismo argentino descripto, ya que abordan una temática circunscripta exclusivamente a las obras, períodos, autores y problemas de las literaturas peninsulares, aunque enfocados desde ejes temáticos y marcos teóricos que ponen en evidencia el desarrollo de una perspectiva transdisciplinaria y transnacional.

El anclaje de la asignatura y los contenidos nucleares señalados por los planes de estudio demarcan el campo específico y son un factor clave para que el diálogo entre disciplinas tenga un cimiento sólido en el campo de conocimiento de pertenencia. En las décadas transcurridas desde los años ochenta - exactamente desde 1983, en un entorno de progresiva normalización de la vida universitaria, consecuencia directa de la normalización de las instituciones democráticas después de la dictadura iniciada en 1976-, el fortalecimiento de los saberes específicos de la literatura española, unido a la apertura de zonas y redes de intercambio disciplinar, ha contribuido a que el hispanismo argentino logre una voz y una identidad propias atravesadas por un prisma de alteridades altamente productivo. En el vasto territorio del hispanismo internacional, por las razones geográficas evidentes y las determinaciones culturales ya expuestas, los estudiosos de la literatura espańola contemporánea en América Latina han encontrado las vías para capitalizar su condición otra en el espectro de las literaturas hispánicas.

\section{Conclusiones}

El hispanismo, tal como se ha perfilado en la universidad latinoamericana y particularmente en Argentina, esto es, en su condición de campo reservado a los Estudios de Literatura Espańola de todas las épocas, presenta en la actualidad signos evidentes de ampliación de su campo con una perspectiva que tiende a integrar, a la manera de la academia norteamericana o europea, todas las literaturas en lengua castellana, en sus múltiples variantes. De momento, esta voluntad de construir una visión ampliada desde el espacio simbólico del hispanismo no parece ser, salvo excepciones, una preocupación que compartan las áreas de las literaturas argentina y latinoamericana; en cambio, las tres por igual demuestran, en grado diverso, interés por borrar las fronteras disciplinarias clásicas y abordar problemas comunes con la participación de 
especialistas provenientes de diferentes espacios y sistemas literarios. El diseño de las carreras de grado según el criterio organizador por literaturas nacionales, como ya se ha explicado, obliga a las iniciativas interdisciplinarias y transnacionales a encauzarse fundamentalmente a través de los proyectos de investigación y de los cursos y carreras de posgrado.

Como se ha visto, estas líneas de trabajo no son incompatibles con la consolidación de las áreas específicas; por el contrario, la perspectiva abierta a otros campos exige en primer lugar que la propia especialización se asiente sobre saberes rigurosos y actualizados.

En esta dirección, el panorama es propicio. Desde los años ochenta del pasado siglo el hispanismo, con su significado y alcance tradicionales, equivalentes a literatura española, ha consolidado su campo y adquirido un perfil propio que se fortalece y afianza en diversos frentes: en primer lugar, en los programas de las asignaturas de la carrera de grado, con distintas soluciones que varían a la hora de estructurar en asignaturas independientes los períodos medieval, siglos de oro y contemporáneo (en pocas universidades se mantienen las tres épocas, en otras fueron reducidas a dos y no faltan aquellas que solo cuentan con una única asignatura de literatura peninsular).

Paralelamente, el campo busca consolidarse con la creación de espacios para el desarrollo científico. Los panoramas sobre principales logros del hispanismo argentino brindados por Romanos (2004) y Chicote (2013) pueden completarse con un recorrido por las actividades desarrolladas por el área de la literatura española en la Universidad Nacional de La Plata desde los años noventa del siglo anterior: además de integrarse en 1995 el Centro de Teoría y Crítica literaria con equipos de investigación sobre temas de la especialidad, en 1999 las dos cátedras de literatura española crearon Olivar, la única revista académica especializada en dicho campo en Argentina. Después de 15 años de trayectoria, la publicación figura indexada en los repertorios más acreditados de publicaciones académicas de las ciencias sociales.

Para no abrumar con la información, baste una última entrada referida a las reuniones científicas más destacas sobre la literatura de España: como se ha mencionado, en 2010 se celebró en la Universidad Nacional de La Plata el X Congreso de la Asociación Argentina de Hispanistas; en 2013 albergó al VII Congreso Internacional de Lyra Minima organizado por la Cátedra de Literatura Española Medieval, y sus resultados merecieron un número 
monográfico de Olivar; finalmente, en mayo de 2015 ambas cátedras de Literatura Española han participado en la organización del IX Congreso Internacional Orbis Tertius de Teoría y Crítica Literaria.

Por su parte, la cátedra de Literatura Española Contemporánea, ante la ausencia de reuniones científicas especialmente dedicadas al tercer período de las letras españolas, impulsó la creación en 2008 del ciclo trienal de reuniones científicas dedicado a la época contemporánea, con sede en la Universidad Nacional de La Plata. En 2011 tuvo lugar el segundo congreso, y en octubre de 2014 se celebró el tercero de los encuentros de la serie bajo el título "III Congreso Internacional de Literatura y Cultura Españolas Contemporáneas. Diálogos transatlánticos: puntos de encuentro". En el acto de apertura fue otorgado el título de Doctor Honoris Causa al escritor y periodista Manuel Vicent, hecho que para el tema que nos ocupa reviste la importancia de ser el primer literato español al que se le otorga el galardón máximo en esta casa de altos estudios, y uno de los pocos intelectuales de esa nacionalidad que lo han recibido en la universidad argentina.

Valga como conclusión y cierre una rápida lectura a las publicaciones y reuniones científicas celebradas en las últimas décadas en Argentina que permite observar la presencia y el crecimiento de un amplio colectivo de especialistas que afronta el reto fundacional de los Estudios Hispánicos en el país austral, esto es, lograr que los espacios académicos específicos dedicados a la literatura española continúen ensanchando su caudal a partir de una perspectiva indefectiblemente domiciliada en el sur, desde la que construye una discursividad propia, instalada en la gran área transnacional del hispanismo pero nutrida de la mejor herencia del hispanismo local y de la tradición de la teoría y crítica literaria argentina que se proyecta con sello propio más allá de las fronteras locales.

La producción académica durante el período iniciado con la reinstauración democrática en Argentina muestra que, en la dirección señalada, el hispanismo ha fortalecido su campo y su identidad mediante un doble movimiento: la afirmación de sus saberes específicos en torno a las letras peninsulares, y la apertura hacia el intercambio con diferentes disciplinas, artes y campos de debate. Ambas tendencias complementarias se revelan como las preferidas y las más eficaces para tender puentes y construir una literatura española internacionalizada y en diálogo. 


\section{BIBLIOGRAFÍA}

Álvarez Barrientos, Joaquín (2010): “Mirar las miradas”, en Álvarez Barrientos, Joaquín (ed.), Memoria del hispanismo. Miradas sobre la cultura española. Madrid: CSIC, pp. 7-13.

Caballero Wangüemert, María (2000): “Canon y corpus. Una aproximación a la literatura hispanoamericana”, en Wentzlaff-Eggebert, Christian/Traine, Martín (eds.), Canon y poder en América Latina. Köln: ASPLA, pp. 33-77.

Chicote, Gloria (2013): “Cuatro postales del hispanismo argentino", en Ínsula, n. ${ }^{\circ}$ 793-794, pp. 34-37.

Delgado, Luisa Elena (2008): "El hispanismo ensimismado", en Macciuci, Raquel, 'Dos nuevas visiones del Hispanismo en Olivar', Olivar, vol. 9, n. ${ }^{\circ}$ 11, pp. 95-99.

Diego, José Luis de (2001): "Presentación de Olivar", en Olivar, vol. 2, n. ${ }^{\circ}$, pp. 255-257.

- (2004): "El hispanismo en Argentina", en Olivar, vol. 5, n. 5, pp. 87-94.

Fernández de Alba, Francisco/Pérez del Solar, Pedro (2006): "Hacia un acercamiento cultural a la literatura hispano-americana”, en Iberoamericana, vol. VI, n. ${ }^{\circ}$ 2, pp. 99-107.

Gallego Cuiñas, Ana (ed.) (2012): Entre la Argentina y España. El espacio transatlántico de la narrativa actual. Madrid/Frankfurt: Iberoamericana/Vervuert.

Gies, David T. (2001): “El Hispanismo que viene: Estados Unidos y Canadá”, en Arbor, vol. ClXviII, n. ${ }^{\circ}$ 664, pp. 493-511.

Macciuci, Raquel (2006a): "Borges, Cortázar, el galache y la gurupa sureña. Apostilla al debate sobre el (anti)hispanismo en Argentina”, en Olivar, vol. 7, n. ${ }^{\circ}$, pp. 125-145.

- (2006b): "Crítica hispánica al Sur. Sobre periferia, centros y des-centramientos", en Orbis Tertius de Teoria y Critica Literaria "Las tradiciones críticas". Orbis Tertius digital, vol. 11, n. ${ }^{\circ} 12$, La Plata: UNLP.

- (2006c): "Literatura española de mar a mar", en Macciuci, Raquel/Corbellini, Natalia (eds.), Del centro a la periferia. Discurso de la otredad en la narrativa española contemporánea. La Plata: Al Margen, pp. 11-50.

OlezA, Joan (2004): “Teoría de la práctica, práctica de la teoría, o práctica teórica. Metaficciones galdosianas", en Arencibia, Yolanda/Prado Escobar, María del/ Quintana, Rosa María (eds.), Galdós y la escritura de la Modernidad. Actas del VII Congreso Internacional Galdosiano. Las Palmas: Cabildo Insular de Gran Canaria, pp. 242-247, <http://www.uv.es/entresiglos/oleza/pdfs/editar> (27-03-2016).

Ortega, Julio (ed.) (2010): Nuevos hispanismos interdisciplinarios y trasatlánticos. Madrid/Frankfurt: Iberoamericana/Vervuert. 
Pastormerlo, Sergio (2006): “Borges, el Quijote y los cervantistas españoles”, en Olivar, vol. 7, n. ${ }^{\circ}$, pp. 119-124.

Pope, Randolph (2008): "El hispanismo dionisíaco”, en Olivar, 11, pp. 91-94.

Pozuelo Yvancos, José María (2009): "Razones para un canon hispánico”, en

Signa: Revista de la Asociación Española de Semiótica, n. ${ }^{\circ}$ 18, pp. 87-97.

Romanos, Melchora (2004): "Procesos de construcción y evolución del concepto

de Hispanismo desde la perspectiva de los estudios de Literatura española”, en Olivar, vol. 5, n. ${ }^{\circ}$ 5, pp. 91-86.

RuIz, Mariana (2013): "Buenos Aires acoge el XVIII Congreso de la Asociación Internacional de Hispanistas", Crónicas de la emigración, <http://www.cronicasdelaemigracion.com/articulo/cronicas/buenos-aires-acoge-xviii-congreso-asociacion-internacional-hispanistas/20130719124019052113.html> (19-07-2013).

Ruiz Mantilla, Jesús (2016): "El lío de Puerto Rico y Estados Unidos”. En: El País, <http://cultura.elpais.com/cultura/2016/03/18/actualidad/1458321002_346014. html> (18-03-2016).

vv. AA. (1995): Dossier sobre el Hispanismo. Quimera. 139, pp. 31-49. 